\title{
Microbiota and Human Reproduction: The Case of Female Infertility
}

\author{
Rossella Tomaiuolo $^{1,2,3}$, Iolanda Veneruso ${ }^{2,3}$, Federica Cariati ${ }^{1,3}$ and Valeria D'Argenio ${ }^{3,4, *(\text { CD }}$ \\ 1 KronosDNA srl, Spinoff of Federico II University, 80133 Napoli, Italy; rossella.tomaiuolo@unina.it (R.T.); \\ cariati@ceinge.unina.it (F.C.) \\ 2 Department of Molecular Medicine and Medical Biotechnologies, Federico II University, Via Sergio Pansini 5, \\ 80131 Napoli, Italy; io.veneruso@studenti.unina.it \\ 3 CEINGE-Biotecnologie Avanzate scarl, Via Gaetano Salvatore 486, 80145 Napoli, Italy \\ 4 Department of Human Sciences and Quality of Life Promotion, San Raffaele Open University, \\ via di val Cannuta 247, 00166 Roma, Italy \\ * Correspondence: dargenio@ceinge.unina.it; Tel.: +39-081-3737909
}

Received: 14 March 2020; Accepted: 28 April 2020; Published: 3 May 2020

\begin{abstract}
During the last decade, the availability of next-generation sequencing-based approaches has revealed the presence of microbial communities in almost all the human body, including the reproductive tract. As for other body sites, this resident microbiota has been involved in the maintenance of a healthy status. As a consequence, alterations due to internal or external factors may lead to microbial dysbiosis and to the development of pathologies. Female reproductive microbiota has also been suggested to affect infertility, and it may play a key role in the success of assisted reproductive technologies, such as embryo implantation and pregnancy care. While the vaginal microbiota is well described, the uterine microbiota is underexplored. This could be due to technical issues, as the uterus is a low biomass environment. Here, we review the state of the art regarding the role of the female reproductive system microbiota in women's health and human reproduction, highlighting its contribution to infertility.
\end{abstract}

Keywords: microbiota; human microbiome; human reproduction; female reproductive system; female infertility

\section{Introduction}

The availability of highly sensitive technologies, i.e., next-generation sequencing, for the in-depth study of microbial communities' composition and richness, has prompted the interest into metagenomics. As a consequence, novel insights regarding the role of the microbiota in human physiology and pathology are gathering [1-3].

This also applies to the female reproductive system [4]. Indeed, for a long-time, culture-based approaches have been used to address the presence of microbes in this body niche and verify their possible implications in human reproduction. More recently, the Human Microbiome Project has assessed that the vaginal microbiota accounts for about $9 \%$ of the whole human microbiota [5-7]. In particular, Lactobacilli have been reported as the most represented bacteria in this body site, other represented genera being Prevotella, Bifidobacterium, Gardnerella, Atopobium, Megasphaera, Sneathia, and Anaerococcus [5-7]. These bacteria have been implicated in different phases of reproduction from gamete formation, fertilization, pregnancy establishment and maintenance, and in the microbial colonization of the fetus and/or of the newborn $[3,4,8]$. As a consequence, many efforts have been made to try to establish the composition and role of the "healthy" female reproductive system microbiome, and the effects of a dysbiosis on human reproduction and fertility $[4,8]$. 
This review aims to summarize the current knowledge regarding the female reproductive system microbiota composition and its role in women's health. In addition, evidence suggesting a link between a dysbiosis of the female reproductive system microbiome and infertility will also be reviewed.

\section{Materials and Methods}

PubMed was searched for indexed articles in English published within 2010 and 2020. The following keywords were used: "female infertility and microbiota", "female infertility and metagenomics", "female reproductive system microbiome", "uterine microbiome", and "vaginal microbiome". A manual search for the oldest references within the resulting articles was performed.

\section{Female Reproductive System Microbiome}

In the last years, increasing evidence has shown the presence of microorganisms not only in the vagina but also in the upper female reproductive system (including the ovaries, the Fallopian tubes, and the uterus), for a long time considered as a sterile niche [4]. Figure 1 summarizes the different bacteria reported so far in the different sections of the female reproductive system, as well as some organs' details (size and $\mathrm{pH}$ ) [9-12].

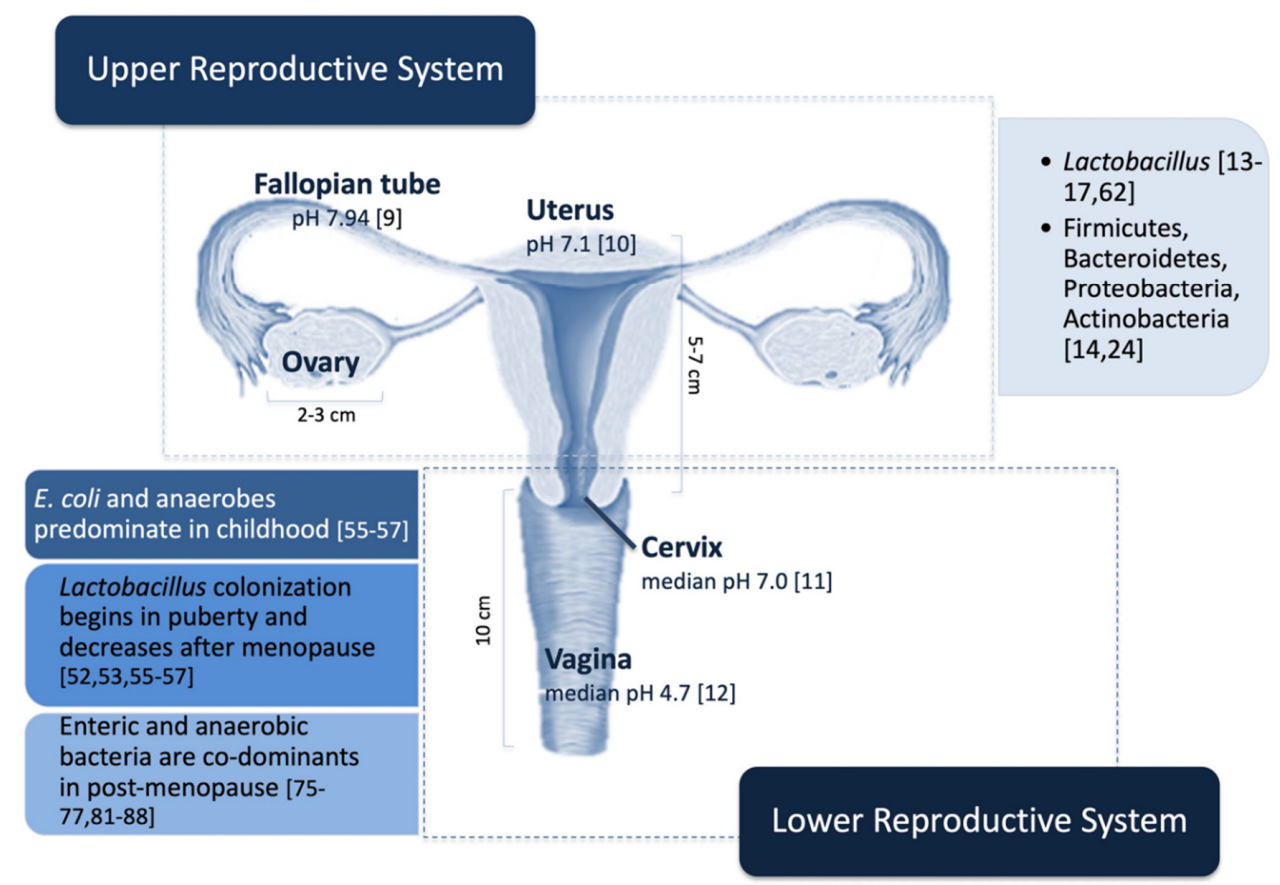

Figure 1. The female reproductive system microbiome in physiological conditions is not sterile but hosts a specific microbiota. In particular, the female upper reproductive system, which also includes the uterus and Fallopian tubes, hosts 10,000 times less bacteria than the vagina. Firmicutes, Bacteroidetes, Proteobacteria, and Actinobacteria have been reported as the most abundant phyla in the endometrium, the Lactobacilli being the most represented genus. The vaginal microbiota, under physiological conditions, undergoes fluctuations attributable to age, lifestyle, and environmental factors. The figure particularly emphasizes the modifications related to sex hormone levels. The $\mathrm{pH}$ values refer to average/median values found in physiological conditions, as $\mathrm{pH}$ also undergoes fluctuations due to several factors, including age, BMI, lifestyle, hormone replacement therapy, and microbiome alterations. References are reported in parentheses.

Interestingly, the Lactobacillus has been identified as the most abundant genus throughout all the female reproductive system [13-17]. These resident microbes contribute to health status maintenance, and their alterations have been associated with several gynecological diseases [18]. Indeed, Lactobacilli have been reported to exert protective effects respect to pathogens' invasion, and a dysbiosis has been 
related to several diseases, including chronic endometritis, endometriosis, pelvic inflammatory disease, and gynecological cancers [15,18].

In this context, several studies have reported a positive correlation between the presence of specific bacteria in the uterus and the onset of pelvic inflammatory disease, an inflammation of the upper genital tract that can lead to infertility $[19,20]$. In addition, an increase of Actinomyces, Corynebacterium, Enterococcus, E. coli, Fusobacterium, Gardnerella, Prevotella, Propionibacterium, Staphylococcus, and Streptococcus has been associated with endometriosis [21-23]. Interestingly, Chen et al. found that the reproductive tract microbiome of women affected by endometriosis was different from that of women with infertility due to other causes [24]. If confirmed in other studies, this suggests that microbiota-specific alterations may lead to a better stratification of infertile women, and also to the development of different therapeutic strategies.

It is important to underline that an increasing number of studies are suggesting that female reproductive system microbes are worth exploring not just in the light of female general and reproductive health, but also of the health of the partner(s) and offspring.

First of all, Dominguez-Bello et al., reviewing the role of the microbiome in human development, highlighted that the host-microbiome superorganism seems to have coevolved to adapt to the environment and survive [25]. In this evolutionary context, the human microbiota has been suggested to be transferred throughout generations, via matrilineal, vertical crossover of bacteria, leading to the transmission of a phylogenetic mark [25]. As a consequence, the female reproductive system microbiota not only is important for women's health but is able to influence the next generation from gestation [3].

Next, even if the uterus is an immune-protected organ, this does not mean constant sterility. In particular, it seems that cervical bacteria may enter with the sperm during fertilization and interact with the egg cells in the first step of embryonic development [25]. This bacterial transmission to the fetus seems to be critical for fertility, as assessed by the observation that gestational infections and inflammations reduce fertility and increase the risk of preterm birth [26]. The maternal microbiota may affect the fetus through several mechanisms, including direct effects (such as immune responses or bacterial metabolites able to cross the placenta) $[27,28]$, and indirect factors able to act as epigenetic modifiers of the fetus (including diet, stress and neuroendocrine factors) [29-31].

Finally, it has been assessed that both gut and vaginal maternal microbiomes vary during pregnancy; however, the significance of these modifications for the mother and/or the newborn is still unclear [32,33]. Koren et al., analyzing the fecal microbiota of 91 pregnant women and their infants, showed that fecal microbiota changes from first to third trimester and, despite a wide interindividual variability, they found an overall increase in Proteobacteria and Actinobacteria, and a reduced richness; interestingly, the third-trimester microbiota was associated with greater inflammation and energy content, able to induce pregnancy-like metabolism in germ-free mice, and impacted pregnant women's metabolisms similar to metabolic syndromes [32]. Blaser and Dominguez-Bello speculated that these pre-partum modifications of the maternal gut microbiota, through the increase of butyrate-producing bacteria, may allow immune tolerance in the mother [34]. A recent study by Farr Zuend et al. highlighted cervicovaginal proteome and microbiome modifications in pregnant, with respect to non-pregnant, women and speculated that these alterations may be related to the increased risk of HIV infection during pregnancy [35]. Further studies are required to clarify how these bacterial modifications can impact women's health and may promote or disadvantage women's fertility.

These data not only underline the role of the resident microbiota for female health's acquisition and maintenance but also suggest that the microbiota may be a novel, important target for the development of specific diagnostic tests or therapies.

\subsection{Upper Reproductive System}

Only recently, metagenomic studies have shown that the female upper reproductive system, which includes the ovaries, the Fallopian tubes, and the uterus (Figure 1), is not sterile but hosts a specific microbiota $[4,8,13-18]$. 
About 30 years ago, bacteria were cultured for the first time in endometrial samples [36]. Later, Mitchell et al. demonstrated the presence in the uterus of specific bacteria, different from those present in the vagina, even if the richness was significantly lower in the uterus [13]. According to the latter, Chen et al., by using both quantitative PCR and next-generation sequencing, revealed that the upper reproductive system hosts 10,000 times less bacteria than the vagina [24]. This lower bacterial load may be due to (i) the cervical barrier that may hamper the ascension of microbes from the vagina, (ii) specific immune reactions, and (iii) environmental factors prompting the growth of specific taxa [4]. Despite this low biomass, the uterine microbiota seems to be active: Firmicutes, Bacteroidetes, Proteobacteria, and Actinobacteria being the most abundant phyla [14,24]. In addition, Lactobacilli have been found to be the most represented genus in the endometrium $[13,14,37]$.

This microbiota has been proposed to be able to modulate the functions of both endometrial cells and the local immune system and to prevent uterine infections by both competing with pathogenic microorganisms and producing protective molecules [38,39].

However, due to the difficulties in obtaining upper reproductive system samples from healthy women, few data are available to date. Moreno et al., comparing the endometrial and vaginal microbiome of fertile and healthy women, confirmed the prevalence of the Lactobacillus and found similar microbiome profiles between the two analyzed body sites in $80 \%$ of the cases [14]. Similar results were achieved by Kyono et al., even if in a small population [15].

Taken together, these data support the hypothesis of a continuum along the reproductive system with the ascension of microbes from the vagina; in addition, a microbial spreading from other organs through the blood has also been suggested $[40,41]$.

However, it is noteworthy that there is still an ongoing debate on whether the upper organs of the female reproductive tract harbor bacteria. Indeed, several studies have used next-generation sequencing methods to assess the presence of bacteria in the placenta and correlate them to different health conditions [41-43]. On the other hand, other studies, taking into account contamination biases due to difficulties in detecting microbes in low-biomass samples, did not detect bacteria in the placenta [44-47]. De Goffau et al. analyzed 537 placental biopsies (318 with adverse outcome and 219 controls) to determine whether pre-eclampsia, delivery of a small-for-gestational-age infant, and spontaneous preterm birth were associated with the presence of specific bacteria, supporting the hypothesis of a placental microbiome [48]. They found that (i) placental samples had very low biomass and most of the bacteria were contaminants; (ii) some bacteria colonize the placenta only during labor and delivery, or are the result of ascending uterine infections; and (iii) the Streptococcus agalactiae was identified as a taxon of placental origin, even if it seems to be not related with the different pregnancy outcomes included in this work [48]. In addition to identifying an alternative route of Streptococcus agalactiae transmission to the infants, this study sheds light on a possible route of fetal colonization already in utero, through the placenta. Perez-Munoz et al. highlighted how evidence supporting the "in utero colonization hypothesis" is still extremely weak, as the used molecular approaches have a detection limit insufficient to analyze "low-biomass" microbial populations, contamination controls are often not taken into account, and bacterial viability is not proven [49]. Indeed, low-biomass samples are extremely difficult to analyze and well-designed, case-control studies on large cohorts of samples, taking into account laboratory contamination sources and other technical limits [50], are required to address the above-mentioned issues. This will allow to establish the functions of the female upper reproductive system microbiome and assess its role in the context of its host, partner, and offspring.

\subsection{Lower Reproductive System}

The vaginal microbiota is the most studied within the female reproductive system (Figure 1). Indeed, vaginal microbiota has been related to vaginal health preservation and host defense against diseases [51]. In healthy, reproductive-age women, the vaginal microbiome accounts for about 1 billion bacteria/gram of vaginal fluid and is featured by low biodiversity, Lactobacillus species accounting for up to $95 \%$ of total bacteria [52,53]. Despite this well-defined composition, there is a certain consensus that 
vaginal microbiota undergoes important composition fluctuations during women's life, sex hormones playing a key role in this scenario [51,54]. Interestingly, the Lactobacillus predominance seems to be age-dependent and strictly related to the reproductive age: in childhood Escherichia coli and anaerobes predominate, with puberty Lactobacillus colonization begins, and finally its abundance decreases after menopause [55-57]. In particular, in post-menopausal women, the estrogen level reduction causes an increase of vaginal $\mathrm{pH}$ that allows the colonization of enteric bacteria and anaerobes that are co-dominant, vary among women, and resemble those found in women with bacterial vaginosis $[51,58]$. Indeed, bacterial vaginosis is the most common form of vaginal dysbiosis and is a condition featured by the shift of vaginal microbiota from Lactobacilli to facultative anaerobe. It is important to underline that the presence of Lactobacilli in the lower female reproductive system has also been related to racial, genetic, geographic, and social factors [59]. Finally, the vaginal microbiota is influenced by several environmental factors, such as hygiene habits, sexual exposure, change of sexual partners, and use and type contraceptives, that may be responsible for microbial fluctuations over time [60-62].

Despite all these variables, Lactobacillus spp. are predominant in this body niche in almost all women, and play an important role in the maintenance of vaginal homeostasis, as underlined by the findings that the depletion of these bacteria has been associated to several diseases [63]. In particular, Lactobacillus crispatus, Lactobacillus gasseri, Lactobacillus iners, and Lactobacillus jensenii are the most represented in the vagina of most healthy women and is yet unclear why other species, such as Lactobacillus helveticus or Lactobacillus acidophilus, are not present [63,64]. Ravel et al. analyzed 396 reproductive-age women and, based on the abundance of the identified Lactobacillus spp., distinguished 5 bacterial profiles [64]. Interestingly, while 4 bacterial profiles (accounting totally for $73 \%$ of the analyzed women) were dominated by a different Lactobacillus spp. (L. crispatus, L. gasseri, L.s iners, and L. jensenii), only one of these profiles was non-Lactobacillus-dominated and was featured by the presence of strictly anaerobic bacteria, such as Atopobium, Dialister, Gardnerella, Megasphaera, Prevotella, and Peptoniphilus [64]. The role of these bacteria in maintaining vaginal health is still under debate $[59,60]$. Indeed, even if these bacteria have been identified in asymptomatic women, they have also been related to a high Nugent score, a common mark of bacterial vaginosis, and has also been related to an increased risk of sexually transmitted diseases and adverse pregnancy outcomes [65].

Dominant Lactobacilli maintain vaginal homeostasis by several direct and indirect antipathogenic mechanisms, such as the formation of microcolonies that, by their adhesion to the epithelial cells, are able to create a physical barrier against pathogens' adhesion, and/or the activation of immune reactions against pathogens [63,66-68]. The production of lactic acid, by lowering the $\mathrm{pH}$, is one of these mechanisms and is able to inactivate or kill several pathogens $[66,67]$. In addition, hydrogen peroxide has also been shown to damage vaginal pathogens and may increase pathogen sensitivity to antibiotics [68].

These molecular mechanisms reinforce the role of Lactobacillus spp. in vaginal health maintenance. As mentioned above, vaginal bacterial dysbiosis is featured by the reduction of Lactobacilli and the increase of anaerobic microorganisms. These modifications are able to produce amino compounds and increase vaginal $\mathrm{pH}$, thus creating an environment more prone to pathogenic infections and more susceptible to unhealthy conditions, including reproductive outcomes [69]. To date, a number of factors, including acquired and modifiable factors (such as diet, tobacco smoke, stress, hygiene practices, sexual habits, use of oral contraceptives, and assumption of probiotics and/or antibiotics), have been associated to vaginal dysbiosis. This allows us to hypothesize that the more our knowledge in this field increases, the more it will be possible to design specific interventions (such as probiotics assumption) that, targeting the vaginal microbiota, will be able to prompt women's health during their lifetimes and reduce the risk of specific diseases onset. As mentioned before, a better understanding of the female reproductive system microbiome and their physiological functions will also help to clarify its contribution to partners' and offspring's health. 


\section{Female Reproductive System Microbiome and Infertility}

Infertility incidence has so increased in the last years that it is currently recognized as a worldwide health issue [70]. One in seven couples is affected by infertility, defined as the inability to conceive after 1 year of regular unprotected intercourse. The first steps of the infertility journey are to investigate the presence of ovulation, uterine cavity anatomy, and patent fallopian tubes in women, and semen parameters in men. The female factors, responsible for $35 \%-40 \%$ of couples' infertility, can depend on several causes, including hormonal changes, tubal changes, uterine pathologies, maternal age, and systemic or genetic diseases. However, about $35 \%$ of couples, despite the above-mentioned clinical and instrumental assessment, still remain with no diagnosis [70]. In vitro fertilization (IVF) techniques offer several opportunities based on the causes and severity of infertility; however, the molecular mechanisms underlying infertility are often unknown, leading to long diagnostic paths and ineffective therapies [70]. Indeed, despite the difficult-to-determine success rate of IVF procedures (because of the indices and patient populations used and/or selection biases and misunderstood statistics), the percentage of implantation and pregnancy rates per embryo transfer still remains low [71,72].

Today, the challenges facing scientists are to recognize the hidden causes of infertility and to improve the efficiency and the efficacy of IVF techniques. Taking into account the previous considerations, the microbiome has been recently considered as a topic of interest for infertility.

Accordingly, an increasing number of studies is highlighting a correlation between infertility and the microbiota $[4,63,73-77]$. Indeed, it has been described that infertile women host a different microbiota, both in the lower and/or in the upper reproductive system, with respect to fertile women $[4,63,73-77]$. Campisciano et al. analyzed the vaginal microbiome of idiopathic infertile women to highlight specific alterations with respect to that of healthy, bacterial-vaginosis-affected, and non-idiopathic infertile women [75]. They not only found a significant clusterization of the four groups but were also able to identify specific bacterial taxa able to distinguish the idiopathic infertile women from the others [75]. Wee et al. retrospectively analyzed vaginal, cervical, and endometrial samples from infertile versus fertile women [76]. This pilot study found that Ureaplasma and Gardnerella were more abundant, respectively, in the vagina and in the cervix of the infertile women [76]. Moreno and Simon recently reviewed the importance of endometrial microbiota for women's health with a special focus on infertility [77]. In addition, it has been suggested that IVF procedures' outcomes may be affected by the resident microbiota (Figure 2).

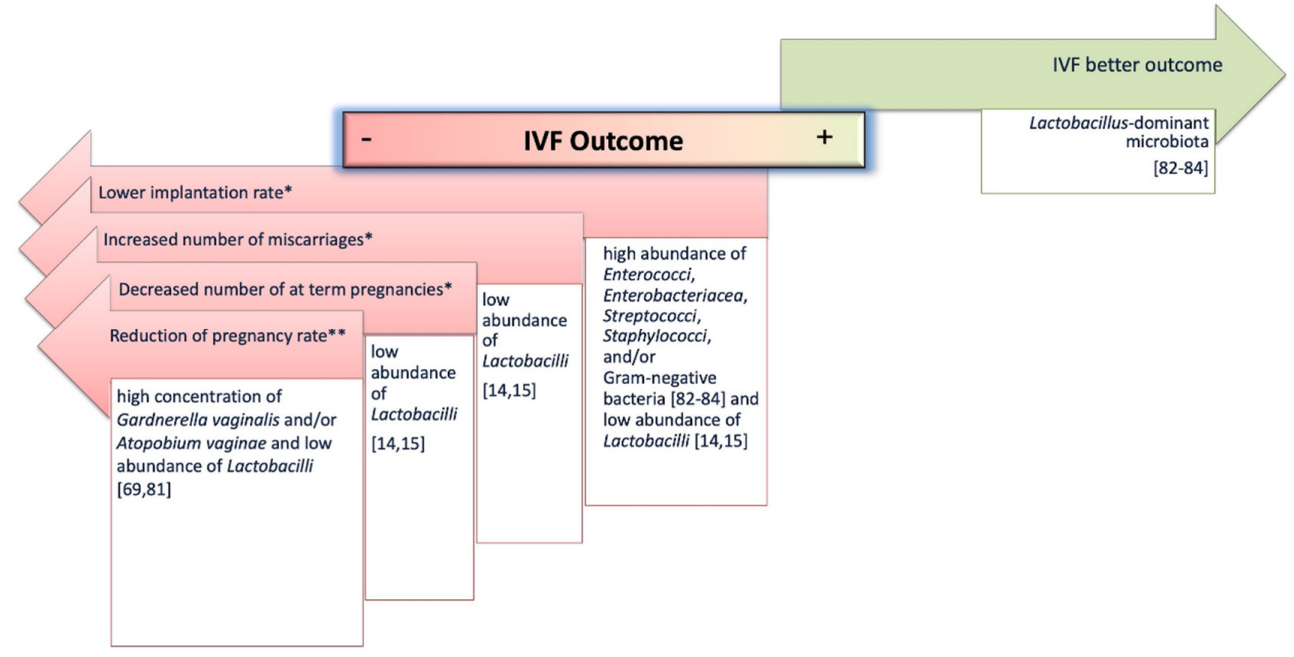

Figure 2. Female reproductive system microbiome alterations have been associated with different IVF outcomes. While Lactobacilli spp. have been reported to exert beneficial effects (green arrow), specific endometrial * or vaginal ${ }^{* *}$ dysbiosis has been related to a worse success rate (pink arrows). References are reported in parentheses. 


\subsection{Female Reproductive System Microbiome and IVF Outcomes}

Taking in to account systematic reviews and meta-analysis data, negative predictors of IVF seems to be female age, duration of infertility, and basal FSH levels [78]. Contrasting data exist about the anti-Müllerian hormone level $[79,80]$. On the contrary, a high number of oocytes and embryo quality are positively associated with good IVF outcome [78]. Nevertheless, there is no significant increase in pregnancy rates after IVF procedures [71,72]. Thus, there is an increasing interest in the identification of additional factors able to affect IVF success rates. In this context, the potential effects of the microbiota on IVF outcomes are currently under investigation, as detailed afterwards.

In particular, alterations of the vaginal microbiota have been correlated to a significant reduction of the pregnancy rate after IVF $[69,81]$. Haar et al., analyzing the vaginal microbiota of 130 IVF patients, found that only a small percentage of those with a vaginal dysbiosis, defined by a high concentration of Gardnerella vaginalis and/or Atopobium vaginae, had a clinical pregnancy, suggesting that vaginal dysbiosis may negatively impact IVF pregnancy rates [81].

Moreover, the association between endometrial microbiome alterations and IVF failure has also been investigated [14,15,37,82-85]. Indeed, the culture of the tips of the catheter used for embryo transfer has revealed that, while the presence of Lactobacilli is associated to a better reproductive outcome, the isolation of Enterococci, Enterobacteriaceae, Streptococci, Staphylococci, and/or Gram-negative bacteria is correlated with lower implantation rate, decreased number of at-term pregnancies and increased number of miscarriages [82-84]. Accordingly, Moreno et al. found that about $46 \%$ of IVF women with a receptive endometrium had a non-Lactobacillus-dominant microbiota and assessed that this microbial profile was associated with a poor reproductive outcome in terms of lower implantation rates, pregnancy rates, ongoing pregnancies, and live birth rates [14]. In addition, Kyono et al. found a different and progressively reduced abundance of Lactobacilli between healthy volunteers, non-IVF patients, and IVF patients $(85.7 \%, 73.9 \%$, and $8 \%$ of relative abundance, respectively), showing that a high number of IVF patients harbor a dysbiotic microbiome at the endometrial level and that a high content of Lactobacilli may improve the implantation rate [15]. However, Franasiak et al., by using $16 \mathrm{~S}$ rRNA sequencing, identified Lactobacillus and Flavobacterium as the most abundant genera on the tips of the catheter used for embryo transfer but were not able to find a statistically significant association among these taxa and patients' IVF outcomes [37]. Recently, Hashimoto et al. analyzed the pregnancy outcomes of 99 IVF patients presenting eubiotic or dysbiotic endometrium at the time of embryo transfer to verify what bacterial profiles are related to the better embryo implantation rate; however, they found no significant differences [85].

All the above highlight the need for further studies to try concluding remarks on the relationship between endometrial dysbiosis and IVF outcomes. If a significant association is confirmed, this will open the way to therapeutic options based on microbiome modifications. Indeed, it is suitable to hypothesize that the modulation of the uterine microbiome, i.e., the increase of Lactobacilli and the decrease of anaerobe microbes (such as Atopobium vaginae, Gardnerella vaginalis, Propionibacterium acnes, and Streptococcus agalactiae) [86], may improve IVF outcomes. In this context, the use of antibiotics is still controversial since no beneficial effects of antibiotic administration before embryo transfer have been reported on pregnancy outcome [87]. However, Vitagliano et al., evaluating the efficacy of antibiotic administration in the treatment of chronic endometritis, found that the treatment not only was effective in eliminating the cause of the infection but had a positive impact on the implantation and pregnancy rate and improved IVF success [88]. Similarly, Cicinelli et al. found that chronic endometritis was prevalent among women with unexplained infertility, and that antibiotic treatment improves spontaneous pregnancy rates and live birth rates in these patients [89].

The use of probiotics may also be useful in these patients; indeed, several oral and vaginal probiotics containing Lactobacillus spp. are available on the market. However, the efficacy of these treatments, alone or coupled with antibiotics, is still under investigation [90-93]. A recent study by Chenoll and colleagues investigated the effects of Lactobacillus rhamnosus BPL005 on the improvement of the female reproductive tract and were able to assess the protective role of this strain on endometrial 
infections in an in vitro model of bacterial colonization of primary endometrial epithelial, suggesting its potential use in gynecological conditions [86].

\subsection{Partner's Semen Microbiota Contribution and Infertility}

While several data are available regarding female infertility, male infertility factors are relatively understudied, and the available data are often contrasting. The male factors considered as potential predictors of IVF outcome include sperm quality parameters and DNA fragmentation [94-96]. In addition, a meta-analysis, including a total of 2906 subjects evaluated in 34 prospective studies, showed that non-conventional assays, such as sperm-zona pellucida-binding and the induced-acrosome reaction, have high predictive power for fertilization outcome [97].

In addition to all the above, it is important to underline that increasing evidence has addressed that to conceive a baby, the reproductive systems of both partners need to work in a proper coordinate manner [70]. This also applies to the microbiome, the semen microbiome being able, through microbial transfer, to affect both couples' and newborns' health [98]. In this context, Mändar et al. analyzed semen and vaginal microbiomes of 23 couples to assess the effects of sexual intercourse on vaginal microbiome [99]. Interestingly, they found that the prevalence of Gardnerella vaginalis in the vaginal microbiome was higher in women whose partners had leukocytospermia; in addition, they also highlighted a reduction of Lactobacillus crispatus and a high concordance between semen and vaginal microbiome, after sexual intercourse [99]. Subsequently, Amato et al. analyzed the vaginal and seminal microbiome of 23 couples with idiopathic infertility with the aim to correlate microbial features with the pregnancy rate after intrauterine insemination [100]. They found that the vaginal microbiome of idiopathic infertile women differed from controls, whereas the semen not; in addition, they found, among the vaginal microbiome of idiopathic infertile women different patterns of Lactobacillus species, Lactobacillus crispatus being associated to the higher rate of intrauterine insemination success [96]. More recently, Štšepetova et al. analyzed the microbiome of native semen samples used for IVF, processed semen samples, and IVF culture media, with the aim to associate them with IVF embryo quality and pregnancy rates [101]. The study highlighted several bacterial changes in the IVF samples; in particular, the presence of Staphylococcus spp. and Alphaproteobacteria may influence sperm and embryo quality, suggesting that methods able to reduce the effects of these bacteria on IVF embryo development may avoid IVF failure [101]. All these data strongly support the hypothesis that semen acts as a medium for the transmission of microorganisms that may potentially become residents in the uterus [102]. In addition, it has also been proposed that males can transmit information to their partners and progeny through the microbiome [103]. Further studies are required to assess the role of this "seminovaginal" microbiome in couples' health, its alterations in infertility, and its ramifications to the offspring.

This strict association may also be used to design targeted therapeutic approaches. For example, Plummer et al. analyzed 22 couples to assess the effect of topical and oral antimicrobial therapy in both women with bacterial vaginosis and their male partners on vaginal and penile microbiomes [104]. Their data showed a reduction of bacterial diversity and the reduced abundance of taxa related to bacterial vaginosis in the vaginal microbiome; the composition of the cutaneous penile microbiome was also modified even if these changes were not stable over time [104]. This study suggests that a combined oral and topical therapy of male partners of women affected by bacterial vaginosis may be effective.

Taken together, these studies highlight the importance of the female reproductive system microbiome for human reproduction, suggesting that microbial dysbiosis not only may be associated with infertility but may also play a role in IVF outcomes. Thus, its evaluation should be taken into account, together with the male semen microbiome, when assessing infertile couples. 


\section{Conclusions}

An increasing number of studies are underlying the importance of the female microbiota in human reproduction and fertility. As for other metagenomic fields, some technical issues have to be carefully taken into consideration in order to minimize potential biases and obtain concluding remarks [49,51]. The uterine microbiota, in particular, due to its low biomass and the difficult sampling (especially in healthy controls), is challenging to be studied. In addition, several internal and external factors can affect the female reproductive system microbiome and have to be taken under consideration to try to minimize intra- and inter-group variability (Figure 3).

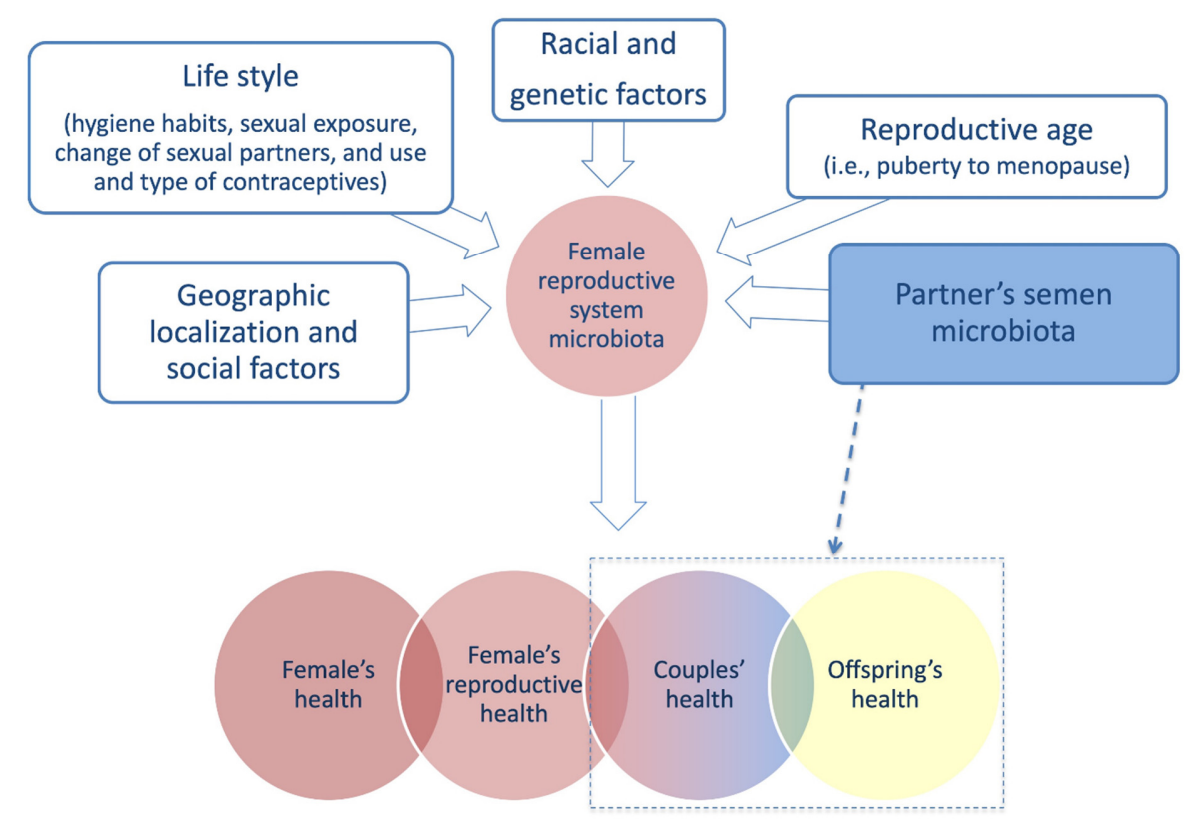

Figure 3. Individual variability factors affecting female reproductive system microbiota composition and processes in which it has been suggested to play a role [54-63,73-77]. The evaluation of the partner's semen microbiota composition is important as it has implications not only on the composition of the female one but also on the reproductive health of the couple and offspring [105].

Finally, to correctly evaluate the reproductive status of a couple, the microbiota evaluation of the male partner is mandatory [70]. It has been recently stated that the reproductive systems of both partners work in a coordinate manner: this sentence also applies to the so-called "seminovaginal" microbiome, meaning a functional unit able to influence not only the couples' health and their reproductive outcomes but also their offspring's health [99,105]. Further studies are required to definitively assess the role of this seminovaginal microbiome in infertility and also in IVF outcomes in order to improve the pregnancy rate. These data may support the utility to test the microbiota in couples' infertility assessment in order to plan the most proper and personalized treatment. Indeed, the microbiome offers a unique opportunity to develop specific treatments aimed at its modification. Several issues still remain to be clarified and, once our knowledge in this field increases, this will open the way to novel opportunities for infertility management and treatment.

Author Contributions: V.D. conceived the study; R.T. and V.D. conceptualized the manuscript content; R.T., I.V., and F.C. wrote the original draft; R.T. and V.D. revised the manuscript. All authors have read and agreed the published version of the manuscript.

Funding: This study was supported by a grant from the European Commission within the Horizon 2020 activities (EIC-SME Instrument 2018-2020 area, N. 855720); and by the EIT Health InnoStars Awards Competition, 2016.

Conflicts of Interest: The authors declare no conflict of interest. 


\section{References}

1. D'Argenio, V.; Salvatore, F. The role of the gut microbiome in the healthy adult status. Clin. Chim. Acta 2015, 451, 97-102. [CrossRef] [PubMed]

2. D'Argenio, V. Human Microbiome Acquisition and Bioinformatic Challenges in Metagenomic Studies. Int. J. Mol. Sci. 2018, 19, 383. [CrossRef] [PubMed]

3. D'Argenio, V. The Prenatal Microbiome: A New Player for Human Health. High Throughput 2018, 7, 38. [CrossRef] [PubMed]

4. Moreno, I.; Simon, C. Deciphering the effect of reproductive tract microbiota on human reproduction. Reprod. Med. Biol. 2018, 18, 40-50. [CrossRef]

5. Human Microbiome Project Consortium. Structure, function and diversity of the healthy human microbiome. Nature 2012, 486, 207-214. [CrossRef]

6. Human Microbiome Project Consortium. A framework for human microbiome research. Nature 2012, 486, 215-221. [CrossRef]

7. González, A.; Vázquez-Baeza, Y.; Knight, R. SnapShot: The human microbiome. Cell 2014, 158, 690. [CrossRef]

8. Franasiak, J.M.; Scott, R.T., Jr. Introduction: Microbiome in human reproduction. Fertil. Steril. 2015, 104, 1341-1343. [CrossRef]

9. Ng, K.Y.B.; Mingels, R.; Morgan, H.; Macklon, N.; Cheong, Y. In Vivo oxygen, temperature and $\mathrm{pH}$ dynamics in the female reproductive tract and their importance in human conception: A systematic review. Hum. Reprod. Update 2018, 24, 15-34. [CrossRef]

10. Parratt, J.R.; Taggart, M.J.; Wray, S. Functional effects of intracellular $\mathrm{pH}$ alteration in the human uterus: Simultaneous measurements of $\mathrm{pH}$ and force. J. Reprod. Fertil. 1995, 105, 71-75. [CrossRef]

11. Eggert-Kruse, W.; Kohler, A.; Rohr, G.; Runnebaum, B. The $\mathrm{pH}$ as an important determinant of sperm-mucus interaction. Fertil. Steril. 1993, 59, 617-628. [CrossRef]

12. Pereira Da Silva, D.; Martinez De Oliveira, J.; Negreiro, F. Observational study of vaginal $\mathrm{pH}$ in healthy Portuguese women. Minerva Ginecol. 2011, 63, 203-212. [PubMed]

13. Mitchell, C.M.; Haick, A.; Nkwopara, E.; Garcia, R.; Rendi, M.; Agnew, K.; Fredricks, D.N.; Eschenbach, D. Colonization of the upper genital tract by vaginal bacterial species in nonpregnant women. Am. J. Obstet. Gynecol. 2015, 212, 611.e1-611.e9. [CrossRef] [PubMed]

14. Moreno, I.; Codoñer, F.M.; Vilella, F.; Valbuena, D.; Martinez-Blanch, J.F.; Jimenez-Almazán, J.; Alonso, R.; Alamá, P.; Remohí, J.; Pellicer, A.; et al. Evidence that the endometrial microbiota has an effect on implantation success or failure. Am. J. Obstet. Gynecol. 2016, 215, 684-703. [CrossRef] [PubMed]

15. Kyono, K.; Hashimoto, T.; Nagai, Y.; Sakuraba, Y. Analysis of endometrial microbiota by 16S ribosomal RNA gene sequencing among infertile patients: A single-center pilot study. Reprod. Med. Biol. 2018, 17, 297-306. [CrossRef]

16. Miles, S.M.; Hardy, B.L.; Merrell, D.S. Investigation of the microbiota of the reproductive tract in women undergoing a total hysterectomy and bilateral salpingo-oopherectomy. Fertil. Steril. 2017, 107, 813-820. [CrossRef]

17. Franasiak, J.M.; Scott, R.T., Jr. Reproductive tract microbiome in assisted reproductive technologies. Fertil. Steril. 2015, 104, 1364-1371. [CrossRef]

18. Moreno, I.; Franasiak, J.M. Endometrial microbiota-new player in town. Fertil. Steril. 2017, 108, 32-39. [CrossRef]

19. Sharma, H.; Tal, R.; Clark, N.A.; Segars, J.H. Microbiota and pelvic inflammatory disease. Semin. Reprod. Med. 2014, 32, 43-49. [CrossRef]

20. Brunham, R.C.; Gottlieb, S.L.; Paavonen, J. Pelvic inflammatory disease. N. Engl. J. Med. 2015, 372, $2039-2048$. [CrossRef]

21. Khan, K.N.; Kitajima, M.; Hiraki, K.; Yamaguchi, N.; Katamine, S.; Matsuyama, T.; Nakashima, M.; Fujishita, A.; Ishimaru, T.; Masuzaki, H. Escherichia coli contamination of menstrual blood and effect of bacterial endotoxin on endometriosis. Fertil. Steril. 2010, 94, 2860-2863.e3. [CrossRef]

22. Khan, K.N.; Fujishita, A.; Kitajima, M.; Hiraki, K.; Nakashima, M.; Masuzaki, H. Intra-uterine microbial colonization and occurrence of endometritis in women with endometriosis. Hum. Reprod. 2014, 29, 2446-2456. [CrossRef] 
23. Khan, K.N.; Fujishita, A.; Masumoto, H.; Muto, H.; Kitajima, M.; Masuzaki, H.; Kitawaki, J. Molecular detection of intrauterine microbial colonization in women with endometriosis. Eur. J. Obstet. Gynecol. Reprod. Biol. 2016, 199, 69-75. [CrossRef]

24. Chen, C.; Song, X.; Wei, W.; Zhong, H.; Dai, J.; Lan, Z.; Li, F.; Yu, X.; Feng, Q.; Wang, Z.; et al. The microbiota continuum along the female reproductive tract and its relation to uterine-related diseases. Nat. Commun. 2017, 8, 875. [CrossRef]

25. Dominguez-Bello, M.G.; Godoy-Vitorino, F.; Knight, R.; Blaser, M.J. Role of the microbiome in human development. Gut 2019, 68, 1108-1114. [CrossRef] [PubMed]

26. Dixon, C.L.; Richardson, L.; Sheller-Miller, S.; Saade, G.; Menon, R. A distinct mechanism of senescence activation in amnion epithelial cells by infection, inflammation, and oxidative stress. Am. J. Reprod. Immunol. 2018, 79, e12790. [CrossRef] [PubMed]

27. Gomez de Agüero, M.; Ganal-Vonarburg, S.C.; Fuhrer, T.; Rupp, S.; Uchimura, Y.; Li, H.; Steinert, A.; Heikenwalder, M.; Hapfelmeier, S.; Sauer, U.; et al. The maternal microbiota drives early postnatal innate immune development. Science 2016, 351, 1296-1302. [CrossRef] [PubMed]

28. Romano-Keeler, J.; Weitkamp, J.H. Maternal influences on fetal microbial colonization and immune development. Pediatr. Res. 2015, 77, 189-195. [CrossRef] [PubMed]

29. Hoffman, D.J.; Reynolds, R.M.; Hardy, D.B. Developmental origins of health and disease: Current knowledge and potential mechanisms. Nutr. Rev. 2017, 75, 951-970. [CrossRef]

30. Weaver, I.C.; Korgan, A.C.; Lee, K.; Wheeler, R.V.; Hundert, A.S.; Goguen, D. Stress and the emerging roles of chromatin remodeling in signal integration and stable transmission of reversible phenotypes. Front. Behav. Neurosci. 2017, 11, 41. [CrossRef]

31. Solomon, O.; Yousefi, P.; Huen, K.; Gunier, R.B.; Escudero-Fung, M.; Barcellos, L.F.; Eskenazi, B.; Holland, N. Prenatal phthalate exposure and altered patterns of DNA methylation in cord blood. Environ. Mol. Mutagen. 2017, 58, 398-410. [CrossRef] [PubMed]

32. Koren, O.; Goodrich, J.K.; Cullender, T.C.; Spor, A.; Laitinen, K.; Kling Bäckhed, H.; Gonzalez, A.; Werner, J.J.; Angenent, L.T.; Knight, R.; et al. Host remodeling of the gut microbiome and metabolic changes during pregnancy. Cell 2012, 150, 470-480. [CrossRef] [PubMed]

33. Aagaard, K.; Riehle, K.; Ma, J.; Segata, N.; Mistretta, T.A.; Coarfa, C.; Raza, S.; Rosenbaum, S.; Van den Veyver, I.; Milosavljevic, A.; et al. A metagenomic approach to characterization of the vaginal microbiome signature in pregnancy. PLoS ONE 2012, 7, e36466. [CrossRef] [PubMed]

34. Blaser, M.J.; Dominguez-Bello, M.G. The Human Microbiome before Birth. Cell Host Microbe 2016, 20, 558-560. [CrossRef]

35. Farr Zuend, C.; Tobin, N.H.; Vera, T.; Kotyrba, L.; Noël-Romas, L.; Birse, K.; Mutch, S.; Li, F.; Lee, D.; McCorrister, S.; et al. Pregnancy associates with alterations to the host and microbial proteome in vaginal mucosa. Am. J. Reprod. Immunol. 2020, 20, e13235. [CrossRef] [PubMed]

36. Eschenbach, D.A.; Rosene, K.; Tompkins, L.S.; Watkins, H.; Gravett, M.G. Endometrial cultures obtained by a triple-lumen method from afebrile and febrile postpartum women. J. Infect. Dis. 1986, 153, 1038-1045. [CrossRef] [PubMed]

37. Franasiak, J.M.; Werner, M.D.; Juneau, C.R.; Tao, X.; Landis, J.; Zhan, Y.; Treff, N.R.; Scott, R.T. Endometrial microbiome at the time of embryo transfer: Next-generation sequencing of the $16 \mathrm{~S}$ ribosomal subunit. J. Assist. Reprod. Genet. 2016, 33, 129-136. [CrossRef]

38. Benner, M.; Ferwerda, G.; Joosten, I.; van der Molen, R.G. How uterine microbiota might be responsible for a receptive, fertile endometrium. Hum. Reprod. Update 2018, 24, 393-415. [CrossRef]

39. Crha, I.; Ventruba, P.; Žáková, J.; Ješeta, M.; Pilka, R.; Lousová, E.; Papíková, Z. Uterine microbiome and endometrial receptivity. Ceska Gynekol. 2019, 84, 49-54.

40. Solt, I. The human microbiome and the great obstetrical syndromes: A new frontier in maternal-fetal medicine. Best Pract. Res. Clin. Obstet. Gynaecol. 2015, 29, 165-175. [CrossRef]

41. Aagaard, K.; Ma, J.; Antony, K.M.; Ganu, R.; Petrosino, J.; Versalovic, J. The placenta harbors a unique microbiome. Sci. Transl. Med. 2014, 6, 237ra65. [CrossRef] [PubMed]

42. Antony, K.M.; Ma, J.; Mitchell, K.B.; Racusin, D.A.; Versalovic, J.; Aagaard, K. The preterm placental microbiome varies in association with excess maternal gestational weight gain. Am. J. Obstet. Gynecol. 2015, 212, 653.e1-653.e16. [CrossRef] [PubMed] 
43. Collado, M.C.; Rautava, S.; Aakko, J.; Isolauri, E.; Salminen, S. Human gut colonisation may be initiated in utero by distinct microbial communities in the placenta and amniotic fluid. Sci. Rep. 2016, 6, 23129. [CrossRef] [PubMed]

44. de Goffau, M.C.; Lager, S.; Salter, S.J.; Wagner, J.; Kronbichler, A.; Charnock-Jones, D.S.; Peacock, S.J.; Smith, G.C.S.; Parkhill, J. Recognizing the reagent microbiome. Nat. Microbiol. 2018, 3, 851-853. [CrossRef]

45. Lauder, A.P.; Roche, A.M.; Sherrill-Mix, S.; Bailey, A.; Laughlin, A.L.; Bittinger, K.; Leite, R.; Elovitz, M.A.; Parry, S.; Bushman, F.D. Comparison of placenta samples with contamination controls does not provide evidence for a distinct placenta microbiota. Microbiome 2016, 4, 29. [CrossRef]

46. Leiby, J.S.; McCormick, K.; Sherrill-Mix, S.; Clarke, E.L.; Kessler, L.R.; Taylor, L.J.; Hofstaedter, C.E.; Roche, A.M.; Mattei, L.M.; Bittinger, K.; et al. Lack of detection of a human placenta microbiome in samples from preterm and term deliveries. Microbiome 2018, 196. [CrossRef]

47. Theis, K.R.; Romero, R.; Winters, A.D.; Greenberg, J.M.; Gomez-Lopez, N.; Alhousseini, A.; Bieda, J.; Maymon, E.; Pacora, P.; Fettweis, J.M.; et al. Does the human placenta delivered at term have a microbiota? Results of cultivation, quantitative real-time PCR, 16S rRNA gene sequencing, and metagenomics. Am. J. Obstet. Gynecol. 2019, 220, 267.e1-267.e39. [CrossRef]

48. de Goffau, M.C.; Lager, S.; Sovio, U.; Gaccioli, F.; Cook, E.; Peacock, S.J.; Parkhill, J.; Charnock-Jones, D.S.; Smith, G.C.S. Human placenta has no microbiome but can contain potential pathogens. Nature 2019, 572, 329-334. [CrossRef]

49. Perez-Muñoz, M.E.; Arrieta, M.C.; Ramer-Tait, A.E.; Walter, J. A critical assessment of the "sterile womb" and "in utero colonization" hypotheses: Implications for research on the pioneer infant microbiome. Microbiome 2017, 5, 48. [CrossRef]

50. Salter, S.J.; Cox, M.J.; Turek, E.M.; Calus, S.T.; Cookson, W.O.; Moffatt, M.F.; Turner, P.; Parkhill, J.; Loman, N.J.; Walker, A.W. Reagent and laboratory contamination can critically impact sequence-based microbiome analyses. BMC Biol. 2014, 12, 87. [CrossRef]

51. Barrientos-Durán, A.; Fuentes-López, A.; de Salazar, A.; Plaza-Díaz, J.; García, F. Reviewing the Composition of Vaginal Microbiota: Inclusion of Nutrition and Probiotic Factors in the Maintenance of Eubiosis. Nutrients 2020, 12, 419. [CrossRef] [PubMed]

52. Delaney, M.L.; Onderdonk, A.B. Nugent score related to vaginal culture in pregnant women. Obstet. Gynecol. 2001, 98, 79-84. [CrossRef] [PubMed]

53. Srinivasan, S.; Liu, C.; Mitchell, C.M.; Fiedler, T.L.; Thomas, K.K.; Agnew, K.J.; Marrazzo, J.M.; Fredricks, D.N. Temporal variability of human vaginal bacteria and relationship with bacterial vaginosis. PLoS ONE 2010, 5, e10197. [CrossRef] [PubMed]

54. Hickey, R.J.; Zhou, X.; Pierson, J.D.; Ravel, J.; Forney, L.J. Understanding vaginal microbiome complexity from an ecological perspective. Transl. Res. 2012, 160, 267-282. [CrossRef]

55. Hammerschlag, M.R.; Alpert, S.; Onderdonk, A.B.; Thurston, P.; Drude, E.; McCormack, W.M.; Bartlett, J.G. Anaerobic microflora of the vagina in children. Am. J. Obstet. Gynecol. 1978, 131, 853-856. [CrossRef]

56. Hammerschlag, M.R.; Alpert, S.; Rosner, I.; Thurston, P.; Semine, D.; McComb, D.; McCormack, W.M. Microbiology of the vagina in children: Normal and potentially pathogenic organisms. Pediatrics 1978, 62, 57-62.

57. Hillier, S.L.; Lau, R.J. Vaginal microflora in postmenopausal women who have not received estrogen replacement therapy. Clin. Infect. Dis. 1997, 25, S123-S126. [CrossRef]

58. Gliniewicz, K.; Schneider, G.M.; Ridenhour, B.J.; Williams, C.J.; Song, Y.; Farage, M.A.; Miller, K.; Forney, L.J. Comparison of the Vaginal Microbiomes of Premenopausal and Postmenopausal Women. Front. Microbiol. 2019, 10, 193. [CrossRef]

59. Anahtar, M.N.; Gootenberg, D.B.; Mitchell, C.M.; Kwon, D.S. Cervicovaginal Microbiota and Reproductive Health: The Virtue of Simplicity. Cell Host Microbe 2018, 23, 159-168. [CrossRef]

60. Gajer, P.; Brotman, R.M.; Bai, G.; Sakamoto, J.; Schütte, U.M.; Zhong, X.; Koenig, S.S.; Fu, L.; Ma, Z.S.; Zhou, X.; et al. Temporal dynamics of the human vaginal microbiota. Sci. Trans. Med. 2012, 4, 132ra52. [CrossRef]

61. Brooks, J.P.; Edwards, D.J.; Blithe, D.L.; Fettweis, J.M.; Serrano, M.G.; Sheth, N.U.; Strauss, J.F., 3rd; Buck, G.A.; Jefferson, K.K. Effects of combined oral contraceptives, depot medroxyprogesterone acetate and the levonorgestrel-releasing intrauterine system on the vaginal microbiome. Contraception 2017, 95, 405-413. [CrossRef] 
62. Noyes, N.; Cho, K.C.; Ravel, J.; Forney, L.J.; Abdo, Z. Associations between sexual habits, menstrual hygiene practices, demographics and the vaginal microbiome as revealed by Bayesian network analysis. PLoS ONE 2018, 13, e0191625. [CrossRef] [PubMed]

63. Younes, J.A.; Lievens, E.; Hummelen, R.; van der Westen, R.; Reid, G.; Petrova, M.I. Women and Their Microbes: The Unexpected Friendship. Trends Microbiol. 2018, 26, 16-32. [CrossRef]

64. Ravel, J.; Gajer, P.; Abdo, Z.; Schneider, G.M.; Koenig, S.S.; McCulle, S.L.; Karlebach, S.; Gorle, R.; Russell, J.; Tacket, C.O.; et al. Vaginal microbiome of reproductive-age women. Proc. Natl. Acad. Sci. USA 2011, 108, 4680-4687. [CrossRef]

65. Jespers, V.; Menten, J.; Smet, H.; Poradosú, S.; Abdellati, S.; Verhelst, R.; Hardy, L.; Buvé, A.; Crucitti, T. BMC Quantification of bacterial species of the vaginal microbiome in different groups of women, using nucleic acid amplification tests. Microbiol 2012, 12, 83.

66. Rönnqvist, P.D.; Forsgren-Brusk, U.B.; Grahn-Håkansson, E.E. Lactobacilli in the female genital tract in relation to other genital microbes and vaginal pH. Acta Obstet. Gynecol. Scand. 2006, 85, 726-735. [CrossRef]

67. Aldunate, M.; Srbinovski, D.; Hearps, A.C.; Latham, C.F.; Ramsland, P.A.; Gugasyan, R.; Cone, R.A.; Tachedjian, G. Antimicrobial and immune modulatory effects of lactic acid and short chain fatty acids produced by vaginal microbiota associated with eubiosis and bacterial vaginosis. Front. Physiol. 2015, 6, 164. [CrossRef]

68. Tachedjian, G.; O'Hanlon, D.E.; Ravel, J. The implausible "in vivo" role of hydrogen peroxide as an antimicrobial factor produced by vaginal microbiota. Microbiome 2018, 6, 29. [CrossRef]

69. Hyman, R.W.; Herndon, C.N.; Jiang, H.; Palm, C.; Fukushima, M.; Bernstein, D.; Vo, K.C.; Zelenko, Z.; Davis, R.W.; Giudice, L.C. The dynamics of the vaginal microbiome during infertility therapy with in vitro fertilization-embryo transfer. J. Assist. Reprod. Genet. 2012, 29, 105-115. [CrossRef]

70. Cariati, F.; D'Argenio, V.; Tomaiuolo, R. The evolving role of genetic tests in reproductive medicine. J. Transl. Med. 2019, 17, 267. [CrossRef]

71. Deonandan, R.; Campbell, M.K.; Østbye, T.; Tummon, I. Toward a More Meaningful In Vitro Fertilization Success Rate. J. Assist. Reprod. Genet. 2000, 17, 498-503. [CrossRef] [PubMed]

72. Fauser, B.C. Towards the Global Coverage of a Unified Registry of IVF Outcomes. Reprod. Biomed. Online 2019, 38, 133-137. [CrossRef] [PubMed]

73. Sirota, I.; Zarek, S.M.; Segars, J.H. Potential influence of the microbiome on infertility and assisted reproductive technology. Semin. Reprod. Med. 2014, 32, 35-42. [CrossRef]

74. Wilson, J.D.; Ralph, S.G.; Rutherford, A.J. Rates of bacterial vaginosis in women undergoing in vitro fertilisation for different types of infertility. BJOG 2002, 109, 714-717. [CrossRef]

75. Campisciano, G.; Florian, F.; D’Eustacchio, A.; Stanković, D.; Ricci, G.; De Seta, F.; Comar, M. Subclinical alteration of the cervical-vaginal microbiome in women with idiopathic infertility. J. Cell Physiol. 2017, 232, 1681-1688. [CrossRef]

76. Wee, B.A.; Thomas, M.; Sweeney, E.L.; Frentiu, F.D.; Samios, M.; Ravel, J.; Gajer, P.; Myers, G.; Timms, P.; Allan, J.A.; et al. A retrospective pilot study to determine whether the reproductive tract microbiota differs between women with a history of infertility and fertile women. Aust. N. Z. J. Obstet. Gynaecol. 2018, 58, 341-348. [CrossRef]

77. Moreno, I.; Simon, C. Relevance of assessing the uterine microbiota in infertility. Fertil. Steril. 2018, 110, 337-343. [CrossRef]

78. van Loendersloot, L.L.; van Wely, M.; Limpens, J.; Bossuyt, P.M.; Repping, S.; van der Veen, F. Predictive Factors in in Vitro Fertilization (IVF): A Systematic Review and Meta-Analysis. Hum. Reprod. Update 2010, 16, 577-589. [CrossRef]

79. Iliodromiti, S.; Kelsey, T.W.; Wu, O.; Anderson, R.A.; Nelson, S.M. The Predictive Accuracy of anti-Müllerian Hormone for Live Birth After Assisted Conception: A Systematic Review and Meta-Analysis of the Literature. Hum. Reprod. Update 2014, 20,560-770. [CrossRef]

80. Tal, R.; Tal, O.; Seifer, B.J.; Seifer, D.B. Antimüllerian hormone as predictor of implantation and clinical pregnancy after assisted conception: A systematic review and meta-analysis. Fertil. Steril. 2015, 103, 119-130. [CrossRef]

81. Haahr, T.; Jensen, J.S.; Thomsen, L.; Duus, L.; Rygaard, K.; Humaidan, P. Abnormal vaginal microbiota may be associated with poor reproductive outcomes: A prospective study in IVF patients. Hum. Reprod. 2016, 31, 795-803. [CrossRef] 
82. Egbase, P.E.; al-Sharhan, M.; al-Othman, S.; al-Mutawa, M.; Udo, E.E.; Grudzinskas, J.G. Incidence of microbial growth from the tip of the embryo transfer catheter after embryo transfer in relation to clinical pregnancy rate following in-vitro fertilization and embryo transfer. Hum. Reprod. 1996, 11, 1687-1689. [CrossRef]

83. Salim, R.; Ben-Shlomo, I.; Colodner, R.; Keness, Y.; Shalev, E. Bacterial colonization of the uterine cervix and success rate in assisted reproduction: Results of a prospective survey. Hum. Reprod. 2002, 17, 337-340. [CrossRef]

84. Selman, H.; Mariani, M.; Barnocchi, N.; Mencacci, A.; Bistoni, F.; Arena, S.; Pizzasegale, S.; Brusco, G.F.; Angelini, A. Examination of bacterial contamination at the time of embryo transfer, and its impact on the IVF/pregnancy outcome. J. Assist. Reprod. Genet. 2007, 24, 395-399. [CrossRef]

85. Hashimoto, T.; Kyono, K. Does dysbiotic endometrium affect blastocyst implantation in IVF patients? J. Assist. Reprod. Genet. 2019, 36, 2471-2479. [CrossRef]

86. Chenoll, E.; Moreno, I.; Sánchez, M.; Garcia-Grau, I.; Silva, Á.; González-Monfort, M.; Genovés, S.; Vilella, F.; Seco-Durban, C.; Simón, C.; et al. Selection of New Probiotics for Endometrial Health. Front. Cell Infect. Microbiol. 2019, 9, 114. [CrossRef]

87. Kroon, B.; Hart, R.J.; Wong, B.M.; Ford, E.; Yazdani, A. Antibiotics prior to embryo transfer in ART. Cochrane Database Syst. Rev. 2012, 3, CD008995. [CrossRef]

88. Vitagliano, A.; Saccardi, C.; Noventa, M.; Di Spiezio Sardo, A.; Saccone, G.; Cicinelli, E.; Pizzi, S.; Andrisani, A.; Litta, P.S. Effects of chronic endometritis therapy on in vitro fertilization outcome in women with repeated implantation failure: A systematic review and meta-analysis. Fertil. Steril. 2018, 110, 103-112. [CrossRef]

89. Cicinelli, E.; Matteo, M.; Trojano, G.; Mitola, P.C.; Tinelli, R.; Vitagliano, A.; Crupano, F.M.; Lepera, A.; Miragliotta, G.; Resta, L. Chronic endometritis in patients with unexplained infertility: Prevalence and effects of antibiotic treatment on spontaneous conception. Am. J. Reprod. Immunol. 2018, 79, 1. [CrossRef]

90. Marcone, V.; Calzolari, E.; Bertini, M. Effectiveness of vaginal administration of Lactobacillus rhamnosus following conventional metronidazole therapy: How to lower the rate of bacterial vaginosis recurrences. New Microbiol. 2008, 31, 429-433.

91. Mastromarino, P.; Macchia, S.; Meggiorini, L.; Trinchieri, V.; Mosca, L.; Perluigi, M.; Midulla, C. Effectiveness of Lactobacillus-containing vaginal tablets in the treatment of symptomatic bacterial vaginosis. Clin. Microbiol. Infect. 2009, 15, 67-74. [CrossRef] [PubMed]

92. Hemmerling, A.; Harrison, W.; Schroeder, A.; Park, J.; Korn, A.; Shiboski, S.; Foster-Rosales, A.; Cohen, C.R. Phase 2a study assessing colonization efficiency, safety, and acceptability of Lactobacillus crispatus CTV-05 in women with bacterial vaginosis. Sex. Transm. Dis. 2010, 37, 745-750. [CrossRef] [PubMed]

93. Bradshaw, C.S.; Pirotta, M.; De Guingand, D.; Hocking, J.S.; Morton, A.N.; Garland, S.M.; Fehler, G.; Morrow, A.; Walker, S.; Vodstrcil, L.A.; et al. Efficacy of oral metronidazole with vaginal clindamycin or vaginal probiotic for bacterial vaginosis: Randomised placebo-controlled double-blind trial. PLOS ONE 2012, 7, e34540. [CrossRef]

94. van Weert, J.M.; Repping, S.; Van Voorhis, B.J.; van der Veen, F.; Bossuyt, P.M.; Mol, B.W. Performance of the postwash total motile sperm count as a predictor of pregnancy at the time of intrauterine insemination: A meta-analysis. Fertil. Steril. 2004, 82, 612-620. [CrossRef]

95. Brincat, D.; Catania, S.; Wismayer, P.S.; Jean Calleja-Agius, J. Male Factors in ART Outcome Prediction. Gynecol. Endocrinol. 2015, 31, 169-175. [CrossRef] [PubMed]

96. Cariati, F.; Borrillo, F.; D'Argenio, V.; Tomaiuolo, R. The laboratory assessment of sperm DNA fragmentation in infertile patients. Biochim. Clin. 2020, 44, 13-20.

97. Oehninger, S.; Franken, D.R.; Sayed, E.; Barroso, G.; Kolm, P. Sperm function assays and their predictive value for fertilization outcome in IVF therapy: A meta-analysis. Hum. Reprod. Update 2000, 6, 160-168. [CrossRef] [PubMed]

98. Altmäe, S.; Franasiak, J.M.; Mändar, R. The seminal microbiome in health and disease. Nat. Rev. Urol. 2019, 16, 703-721. [CrossRef]

99. Mändar, R.; Punab, M.; Borovkova, N.; Lapp, E.; Kiiker, R.; Korrovits, P.; Metspalu, A.; Krjutškov, K.; Nõlvak, H.; Preem, J.K.; et al. Complementary seminovaginal microbiome in couples. Res. Microbiol. 2015, 166, 440-447. [CrossRef] 
100. Amato, V.; Papaleo, E.; Pasciuta, R.; Viganò, P.; Ferrarese, R.; Clementi, N.; Sanchez, A.M.; Quaranta, L.; Burioni, R.; Ambrosi, A.; et al. Differential Composition of Vaginal Microbiome, but Not of Seminal Microbiome, Is Associated with Successful Intrauterine Insemination in Couples With Idiopathic Infertility: A Prospective Observational Study. Open Forum Infect. Dis. 2019, 7, ofz525. [CrossRef]

101. Štšepetova, J.; Baranova, J.; Simm, J.; Parm, Ü.; Rööp, T.; Sokmann, S.; Korrovits, P.; Jaagura, M.; Rosenstein, K.; Salumets, A.; et al. The complex microbiome from native semen to embryo culture environment in human in vitro fertilization procedure. Reprod. Biol. Endocrinol. 2020, 18, 3. [CrossRef]

102. Altmäe, S. Commentary: Uterine Microbiota: Residents, Tourists, or Invaders? Front. Immunol. 2018, 9, 1874. [CrossRef] [PubMed]

103. Rando, O.J.; Simmons, R.A. I'm eating for two: Parental dietary effects on offspring metabolism. Cell 2015, 161, 93-105. [CrossRef] [PubMed]

104. Plummer, E.L.; Vodstrcil, L.A.; Danielewski, J.A.; Murray, G.L.; Fairley, C.K.; Garland, S.M.; Hocking, J.S.; Tabrizi, S.N.; Bradshaw, C.S. Combined oral and topical antimicrobial therapy for male partners of women with bacterial vaginosis: Acceptability, tolerability and impact on the genital microbiota of couples-A pilot study. PLoS ONE 2018, 13, e0190199. [CrossRef] [PubMed]

105. Tomaiuolo, R.; Veneruso, I.; Cariati, F.; D'Argenio, V. Microbiota and Human reproduction: The case of male infertility. High Throughput 2020, 9, 10. [CrossRef]

(C) 2020 by the authors. Licensee MDPI, Basel, Switzerland. This article is an open access article distributed under the terms and conditions of the Creative Commons Attribution (CC BY) license (http://creativecommons.org/licenses/by/4.0/). 